\title{
ROYAL SOCIETY \\ New Foreign Members
}

\section{Le Duc de Broglie}

Maurice, Duc de Broglie, was born in 1875, and has made important contributions to the study of $\mathrm{X}$-rays and the establishment of the now well-known scheme of X-ray electron shells. In 1913, soon after the discovery of the diffraction of X-rays by crystals, he devised a photographic method of investigating $\mathrm{X}$-ray spectra, similar to that developed independently by Moseley in Manchester. During 1920-1922 he used the method of semicircular focusing in a magnetic field to investigate the secondary electrons obtained from these films by the absorption of $\mathrm{X}$-rays. In this way he obtained a direct and beautiful confirmation of the existence of electron energy-levels and of the X-ray quanta. About this time he wrote "Les Rayons X", which was for some years the best account of these phenomena. More recently, the Duc de Broglie has worked on the Brownian movement, on the total reflection of X-rays and on neutron emission. He has served on many committees of the Paris Academy of Sciences, and in 1937 became a member of the Conseil National des Recherches Scientifiques et Industrielles.

\section{Prof. R. G. Harrison}

Prof. Ross Granville Harrison, of Yale University, is one of the most distinguished experimental zoologists of to-day. $\mathrm{He}$ is probably best known as the originator of tissue culture, his first experiments in this direction being published in 1907. He showed that pieces of the medullary cord of frog embryos could be kept alive in clotted lymph, and he observed the outgrowth of nerve fibres from the explants. Thus he not only originated the method of tissue culture, but also used it, as it should be used, to solve a general problem, namely, that of the mode of origin of nerve fibres. In his later work, he has not by any means confined himself to the tissue culture technique, or even to the problems of the development of the nervous system, important though his contributions to both these fields have been. But, employing grafting methods, he opened up the very important question of the influence of the body of an embryo on the orientation and symmetry of organs grafted into it ; and he initiated what is probably the most fundamental approach yet made to the problem of relative growth.

In all these fields, Prof. Harrison's work has been characterized by extreme clarity and precision. His papers are exemplary models, both in contents and presentation, for all young experimental morphologists ; and they can be recommended as an antidote to those who think that there can be no exact biology except in those fields within reach of physical and chemical methods; while his Croonian Lecture on the origin and development of the nervous system, given in 1935, is a beautiful example of a broad and penetrating analysis of a biological problem.

\section{Prof. G. N. Lewis}

Prof. Gimbert Newton Lewis, of the University of California, is well known for his important experimental researches in electrochemistry. In this field he and his pupils have made some very accurate measurements in difficult fields, including determinations of the electrode potentials of the alkali metals. This work links up with Prof. Lewis's outstanding contributions to thermodynamics, in which he introduced the very original and serviceable conception of the activity. This has been of fundamental importance in the development of the study of strong electrolytes, to which Prof. Lewis and his pupils have made many valuable contributions, and also proved to be very closely connected with the theoretical developments of the subject made by Debye and Hückel.

Another theoretical contribution made by Prof. Lewis was the explanation of covalency as due to electron sharing, and this conception is now firmly established in the modern theory of valency. There are few fields of modern physical chemistry which do not owe something to the highly original and constructive work of Prof. Lewis, and the systematization of thermodynamic data by him and his pupils has also been very important in the application of physical chemistry to industry.

\section{Dr. Francis Peyton Rous}

Dr. Rous is a graduate of Johns Hopkins University and has worked at the Rockefeller Institute for Medical Research, New York, since 1909. He is best known for his researches on the problem of transmission of cancer. More than thirty years ago he found a spontaneous sarcoma in a barred Plymouth Rock hen which could be transplanted into other individuals of stock closely related to the fowl in which the growth originally occurred. The fragments of tissue which produced new tumours on injection into other chickens did not contain any visible organisms, and extracts of the ground tumour material produced fresh sarcomata on injection into other fowls even after filtration through apparatus which would retain very small micro-organisms. The tumour, known as the Chicken Tumour I, or the 'Rous sarcoma', retained its distinctive properties whether it was transmitted by a graft of living tissue, by a cell-free filtrate or by dried tumour material, and it is still propagated at the present day. Rous later found many other fowl tumours.

During the last few years Dr. Rous has investigated the Shope rabbit papilloma virus. He has also worked on many physiological problems concerning the liver and blood vessels, the reaction of tissues to injury and vital stains and the preservation of blood. The papers describing the transmissible fowl tumours are classical for accuracy of observations recorded, and for deductions placed on the results. 